\title{
Students Adding Value: Improving Patient Care Measures While Learning Valuable Population Health Skills
}

\author{
Amy W. Shaheen, MD, MSc', Kelly Bossenbroek Fedoriw, MD', \\ Susanna Khachaturyan, MSW, MPH', Beat Steiner, MD, MPH', \\ Julie Golding, BS', Julie S. Byerley, MD, MPH', \\ Erika S. Helgeson, PhD ${ }^{2}$, and Gary L. Beck Dallaghan, PhD' ${ }^{\prime}$
}

\begin{abstract}
Medical students are potential resources for ambulatory primary care practices if learning goals can align with clinical needs. The authors introduced a quality improvement (QI) curriculum in the ambulatory clinical rotation that matched student learning expectations with practice needs. In 2016-20I7, 128 students were assigned to academic, university affiliated, community health, and private practices. Student project measures were matched with appropriate outcome measures on monthly practice dashboards. Binomial mixed effects models were used to model QI measures. For university collaborative practices with student involvement, the estimated odds of a patient being screened for breast cancer in March 2017 was approximately 2 times greater than in 2016 . This odds ratio was $36.2 \%$ greater than the comparable odds ratio for collaborative practices without student involvement $(95 \%$ confidence interval $=22.7 \%$ to $51.2 \%$ greater). When student curriculum and assignments align with practice needs, practice metrics improve and students contribute to improvements in real-world settings.
\end{abstract}

\section{Keywords}

medical students, quality metrics, population health, medical school curriculum

In addition to patient care, ambulatory providers have many competing demands including electronic health records, quality goals, and patient volume expectations. Given the priorities of providers, health systems, and community practices, little time or priority is given to medical student education. ${ }^{1,2}$ Yet, accrediting bodies such as the Liaison Committee on Medical Education and the Higher Learning Commission require student experiences in the ambulatory setting. Schools of medicine (SOMs) face challenges incorporating students into and strengthening ambulatory learning in busy ambulatory settings. ${ }^{3-5}$ These competing priorities of health systems and SOMs have led to a mismatch of supply and demand with more students competing for a limited number of preceptor sites.

Parallel to the demand for increased ambulatory learning sites is the growing pressure on ambulatory practices to meet quality metrics. Reimbursement is increasingly tied to meeting such metrics, but practices often do not have the resources to dedicate to quality improvement (QI) efforts. Medical students are an untapped resource to help practices achieve quality goals while at the same time learning the crucial skills of QI.
Incorporating students into QI efforts has the potential to transform students from a practice burden to a valuable resource while improving the educational value of ambulatory rotations. Wong and Holmboe ${ }^{6}$ propose "aligning educational and clinical outcomes ... reframing some activities as important educational opportunities." Specifically, they suggest faculty with QI expertise work alongside learners and other interprofessional team members on a QI project that is integrated into institutional safety and quality initiatives. Although some published reports describe systematic efforts to implement a curriculum designed to directly improve care, most describe the efforts of residents or describe small pilot programs of medical students, frequently measuring knowledge and

\footnotetext{
'University of North Carolina in Chapel Hill, NC

${ }^{2}$ University of Minnesota, Minneapolis, MN

\section{Corresponding Author:}

Amy W. Shaheen, Department of Medicine, University of North Carolina in Chapel Hill, CB\#7I I0, I0I Manning Drive, Chapel Hill, NC 27599

Email: Shaheen@med.unc.edu
} 
not patient outcomes - the highest level of impact attainable on the Kirkpatrick model. ${ }^{6-13}$ To the research team's knowledge, few SOMs have attempted curricular change for the systematic incorporation of students in ambulatory population health efforts and none have measured the impact of that curriculum on patient outcomes (Shaheen AW et al, unpublished data, 2018).

The research team hypothesized that students learning QI and applying those skills in clinical practices would bring value to the practices as the practices similarly brought value to the student's clinical learning. ${ }^{14}$ The study aim was to systematically integrate a QI curriculum for all students into their ambulatory clinical rotation and measure the impact of that curriculum on practice clinical measures.

\section{Methods}

This study took place at a public university SOM in the southeastern United States. In March 2016, the SOM implemented a new curriculum to include a 16-week ambulatory course for all third-year medical students that replaced the traditional family medicine, outpatient internal medicine, and outpatient pediatric block schedules. Each student was assigned 2 days in an adult primary care (either internal medicine or family medicine) practice and 1 day in a pediatric primary care practice every week to learn clinical ambulatory medicine. The remaining 2 days each week were for lectures, elective patient care experiences, QI, and self-directed learning.

This study (\#16-2401) was reviewed by the Office of Human Research Ethics, which determined that it does not constitute human subjects research as defined under federal regulations [45 CFR 46.102 (d or f) and 21 CFR $56.102(\mathrm{c})(\mathrm{e})(\mathrm{l})]$ and does not require institutional review board approval.

\section{Curriculum}

Parallel to the clinical curriculum, an innovative population health and QI curriculum was implemented, which included engagement in a QI project for all 128 students. The SOM has a vertically and horizontally integrated comprehensive health systems science curriculum based on the AMA Health Systems sciences text book..$^{15}$ The 16-week ambulatory course was tasked by the SOM curriculum committee to deliver the QI and population health curriculum. Working with the local QI education group and the lead author, who has expertise in QI, a curriculum was developed to teach understanding the need for QI in health care, QI methods and language, the use of QI tools, team composition, and the use of data in QI. When possible, the readily available and free online curriculum from the Institute for Healthcare Improvement
(IHI) was used. ${ }^{16}$ Based on the proposed learning objectives, 7 web-based IHI modules were chosen to be completed by each student during the first 6 weeks (Table 1). ${ }^{16}$ Additionally, in 4 classroom sessions (Table 1), students learned and discussed social determinants of health and impact on QI efforts, variance in data, the benefit of interprofessional teams, and gaps between best evidence and practice. Students also learned QI strategies used to close quality gaps in a population, including driver diagrams, SMART (specific, measurable, achievable, relevant, and time-bound) aim statements, and the use of Plan-Do-Study-Act (PDSA) cycles (Table 1).

A QI project requirement gave students an opportunity to put learning into practice and contribute to the clinics' improvement efforts using PDSA cycles. These projects were identified while working with clinicians, and the students were given dedicated time in their schedules to work on the projects, averaging 8 half-day sessions per 16 weeks. Formative feedback was provided by another student (chosen by the students) on the first PDSA cycle using a Quality Improvement Proposal Assessment Tool (QIPAT) ${ }^{17}$ Finally, one of 3 faculty members used QIPAT to provide a second round of formative feedback (including comments) on the first PDSA by week 8 for all students.

\section{Faculty Development}

Preceptors were encouraged to attend faculty development sessions that were offered twice during each 16-week block and included 2 hours of interactive learning as well as dinner. Faculty development focused on project choice, educational value of projects, practice support and alignment, and basic QI methods and language. Student attendance was required to promote discussion of practice projects with faculty.

\section{Practices}

Practice types included University academic practices (ACA), practices owned by the University Health System (AP), Community Health Centers (CHC), and private practices with no health system financial affiliation.

\section{Outcomes}

The research team measured practice quality metrics, comparing practices with and without students. The effects on quality metrics were measured using monthly dashboards available for $\mathrm{ACA}, \mathrm{AP}$, and $\mathrm{CHC}$ when student projects aligned with practice dashboards. The dashboards represent institutional or systems' priorities for care. Monthly dashboards for private practices were not available and only descriptive data based on student-reported projects 
Table I. Population Health and Quality Improvement Curriculum over 16 Weeks ${ }^{\mathrm{a}}$.

Curricular Space and Timing

Session I: I hour

Weeks 2-4: Online

Session 2: I hour

Week 5: In the practice

Week 6: Online

Week 7: Online

Week 8: In the practice

Week 9: Session 3: 30 minutes

Week I2: Session 4: 30 minutes

Topics (Regular Script) and Student Assignments/Deliverables (in Italics)

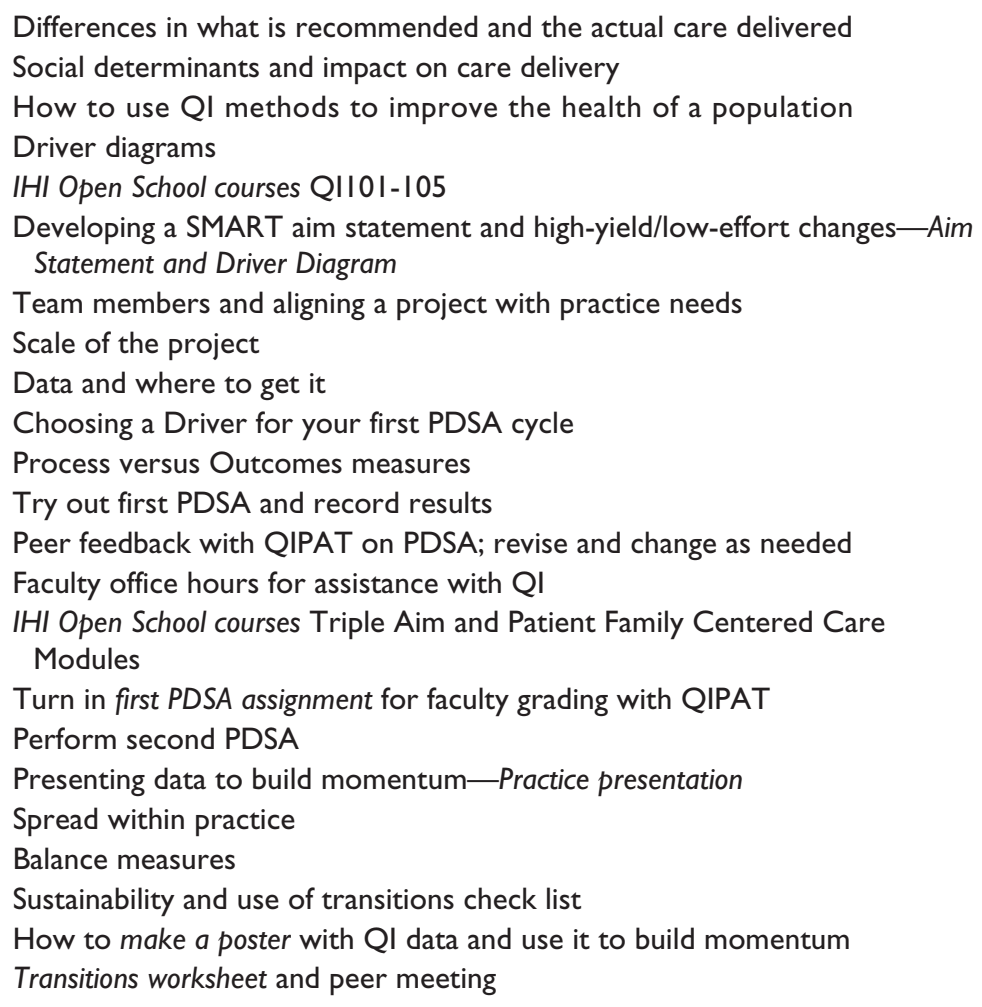

Differences in what is recommended and the actual care delivered

How to use QI methods to improve the health of a population

Driver diagrams

IHI Open School courses QIIOI-I05

Developing a SMART aim statement and high-yield/low-effort changes-Aim Statement and Driver Diagram

Team members and aligning a project with practice needs

oject

Data and where to get it

Phoosing a Driver for your first

Try out first PDSA and record results

Peer feedback with QIPAT on PDSA; revise and change as needed

Faculty office hours for assistance with QI

IHI Open School courses Triple Aim and Patient Family Centered Care

Perform second PDSA

Presenting data to build momentum-Practice presentation

Spread within practice

Balance measures

How to make a poster with QI data and use it to build momentum

Transitions worksheet and peer meeting

Abbreviations: IHI, Institute for Healthcare Improvement; PDSA, Plan-Do-Study-Act; QI, quality improvement; QIPAT, Quality Improvement Project Assessment Tool; SMART, specific, measureable, actionable, relevant, timely.

${ }^{a}$ Sessions involve face-to-face time with course director. Other curriculum was web-based and self-study.

are included in study results. In all cases, the team strongly suggested student projects align with practice measures of quality so that student impact could be measured using these available data. Most ACA and AP practices belong to a primary care quality collaborative that is composed of 24 community-affiliated practices (AP) and 2 academic (ACA) practices. One AP practice that hosted students did not belong to the quality collaborative. Because the team felt that practices in the collaborative may be qualitatively different than practices that did not participate in the collaborative, this AP practice was analyzed separately and data from that one AP practice with a student were compared to other non-collaborative AP practices without students. Estimates and confidence intervals are provided for this practice.

Different work by the research team examined the impact of this curriculum on traditional measures of student satisfaction, student performance, as well as on preceptor recruitment (Shaheen AW et al, unpublished data, 2018). Quality measures on practice dashboards were evaluated for ACA, AP, and CHC practices. For private practices, conditions most commonly targeted by student efforts were categorized. For the purposes of this article, only measures of effect of the curriculum on practice quality metrics are reported; specifically, practice metrics on which students worked were compared with the same metrics at practices that had no student engagement.

\section{Statistical Analysis}

Because quality metrics are reported as the proportion of eligible patients attaining appropriate screening or control goals, binomial mixed effects models were used to model QI measures. These models were fit for each metric and each type of practice (ACA, AP, and $\mathrm{CHC}$ ).

Mixed effects models were used because they account for the inherent variability in quality metrics between practices and the correlation between repeated measures within the same practice. The models included a random intercept for each practice and fixed effects for year, student assignment to the practice at any time during the given year, and the interaction between year and student assignment. The research team assessed both the direct (student(s) assigned to improve specific metric) and indirect (student(s) assigned 
Table 2. Project Choice and Number of Students in Each Area.

\begin{tabular}{|c|c|c|c|c|c|}
\hline Project Focus & $\operatorname{ACA}(n=2)$ & $\mathrm{AP}(\mathrm{n}=20)$ & $\mathrm{CHC}(\mathrm{n}=6)$ & $\mathrm{PP}(\mathrm{n}=30)$ & Total Projects \\
\hline Diabetes & $4^{\mathrm{a}}$ & $8^{\mathrm{a}}$ & $4^{\mathrm{a}}$ & 9 & 25 \\
\hline Colorectal cancer screening & $3^{\mathrm{a}}$ & $\mathrm{I}^{\mathrm{a}}$ & $1 \mathrm{I}^{\mathrm{a}}$ & 2 & 17 \\
\hline Breast cancer screening & $\mathrm{I}^{\mathrm{a}}$ & $2^{a}$ & $2^{\mathrm{a}}$ & 2 & 7 \\
\hline Cervical cancer screening & $3^{\mathrm{a}}$ & $6^{a}$ & $0^{\mathrm{a}}$ & 0 & 9 \\
\hline HPV vaccination & 0 & I & 2 & 4 & 7 \\
\hline Pneumococcal vaccine & $2^{a}$ & $2^{a}$ & 0 & 0 & 4 \\
\hline Clinic flow & 0 & 0 & 5 & 2 & 7 \\
\hline Falls & $0^{\mathrm{a}}$ & $0^{\mathrm{a}}$ & 2 & I & 3 \\
\hline Blood pressure/HTN & 0 & 0 & $3^{\mathrm{a}}$ & 0 & 3 \\
\hline Chronic pain/opiate management & 0 & 0 & $\mathrm{I}^{\mathrm{a}}$ & 7 & 8 \\
\hline Hotspotting/high utilizer patients & 3 & 0 & 0 & 0 & 3 \\
\hline COPD & $2^{a}$ & 0 & 0 & 0 & 2 \\
\hline Decrease ER visits & $I^{\mathrm{a}}$ & $0^{\mathrm{a}}$ & 0 & I & 2 \\
\hline Mental health & $\mathrm{I}^{\mathrm{a}}$ & $0^{\mathrm{a}}$ & 0 & 10 & II \\
\hline Other & 0 & 2 & 4 & 14 & 20 \\
\hline Total by site & 20 & 22 & 34 & 52 & 128 \\
\hline
\end{tabular}

Abbreviations: ACA, practice and physicians at School of Medicine; AP, physicians employed and practices owned by Health Care System; CHC, Community Health Centers; COPD, chronic obstructive pulmonary disease; ER, emergency room; HPV, human papillomavirus; HTN, hypertension; PP, private practices.

${ }^{a}$ Institutional or system goal $\mathrm{n}$ represents the number of practice sites.

to improve alternate metric) association between student assignment to the practice and change in quality metrics. Wald tests were used to compare the change in quality metrics from 2016 to 2017 (expressed as odds ratios) between practices with and without students. $P$ values were not adjusted for multiple comparisons. Statistical analyses were conducted using SAS 9.4 (SAS Institute Inc., Cary, North Carolina), and graphical depictions were created using the ggplot2_2.2.1 package in $\mathrm{R}$ version 3.4.1 (R Foundation for Statistical Computing, Vienna, Austria).

\section{Results}

A total of 128 students completed the ambulatory course between March 2016 and February 2017, and the majority of projects aligned with institutional or practice goals per the recommendations of the course instructors (Table 2). For example, diabetes control and screening for cancers such as breast, cervical, and colorectal are quality outcomes the clinics use as goals for the clinical practices.

\section{Practice Measures}

Student effects on quality measures for which there were data (March 2016 and March 2017) are shown for CHC and for ACA and AP (Figures 1 and 2). If at any time in the given year a student worked on a project with measures noted in the dashboard, the year-overyear change in the metric for that practice is shown. Although Figures 1 and 2 show outcomes of practice metrics, students and providers typically chose to improve process measures with the intent of those process improvements leading to improved outcomes measures. Examples included the percent of the time stool tests were given to eligible patients or mailed back to the clinic, with the hopeful outcome of improving colorectal cancer screening rates. Similarly, the percent of the time mammograms were scheduled for uninsured patients to improve overall mammography screening rates, and the percentage of patients given a depression screener at check-in to improve depression-screening rates.

Cancer screening was a popular target for improvement strategies. Practices with direct student involvement showed increases in cancer screening metrics for which there were data (Figure 1 and online Supplementary Table 1). Changes in breast cancer screening, colorectal cancer screening in university practices within the primary care collaborative, and cervical cancer screening from March 2016 to March 2017 were significantly greater in practices with direct student involvement than practices without student involvement. The largest increases were seen in breast cancer and cervical cancer screening. For all university collaborative practices with student involvement, the estimated odds of a patient being screened for breast cancer in March 2017 was approximately 2 times greater than in 2016. This odds ratio was $36.2 \%$ greater than the comparable odds ratio for collaborative practices without student involvement (95\% confidence interval $[\mathrm{CI}]=22.7 \%$ to $51.2 \%$ greater $)$. Similarly, the odds ratio 


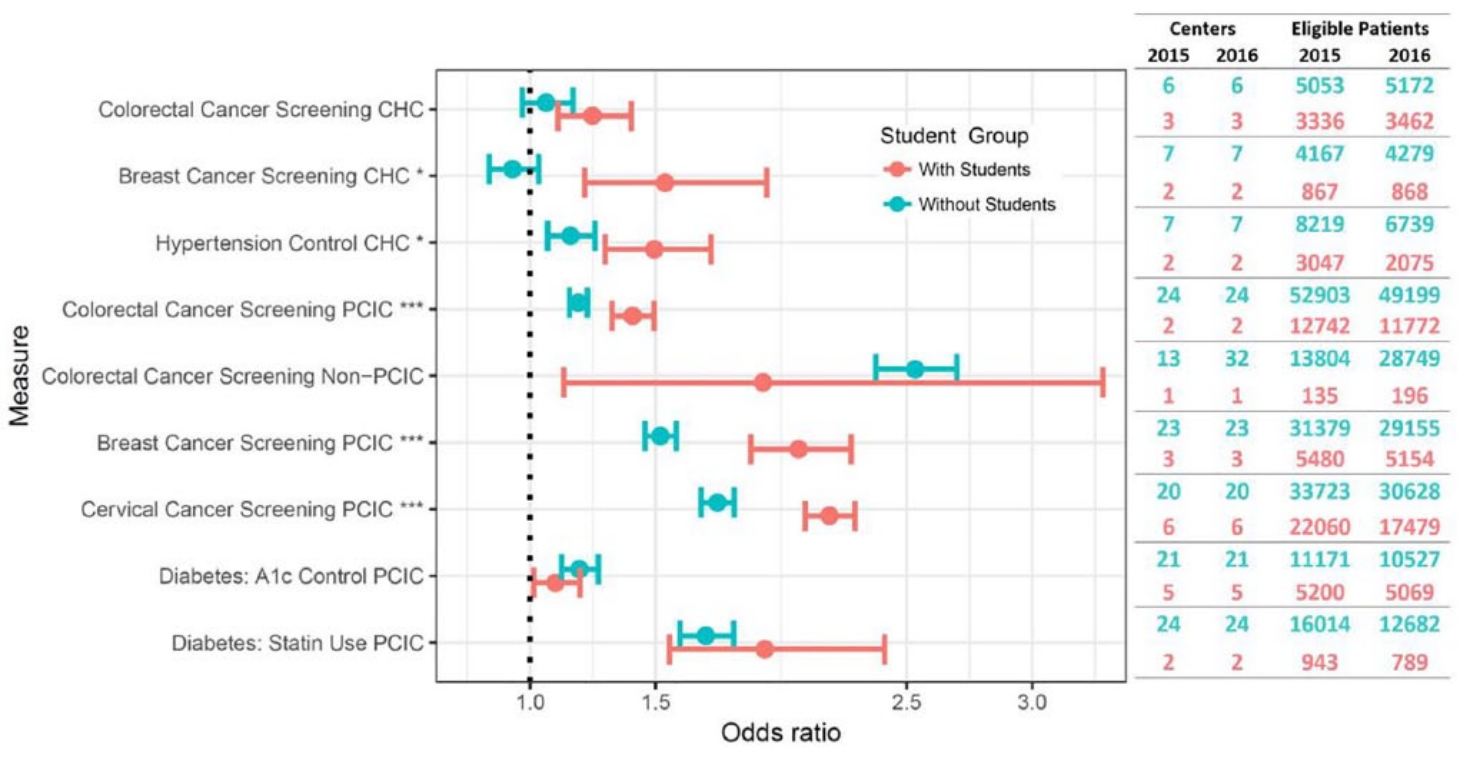

Figure I. Model estimated odds ratios illustrating the association between change in quality measures and direct student involvement.

The odds ratios represent the change in odds of a patient achieving appropriate screening or control goals from March 2017 to March 2016. Odds ratios $<I$ indicate improvement in quality metrics, whereas odds ratios $<I$ indicate a decrease in quality metrics between the years. $\mathrm{PCIC}$, all university academic practices (ACA) and practices owned by the university health system (AP) in the primary care improvement collaborative; non-PCIC, all AP not in the primary care improvement collaborative; $\mathrm{CHC}$, Community Health Centers. Odds ratio estimates and $95 \%$ confidence intervals are presented. $P$ values have not been adjusted for multiple comparisons.

$* P<.01, * * P<.001$, $* * * P<.0001$.

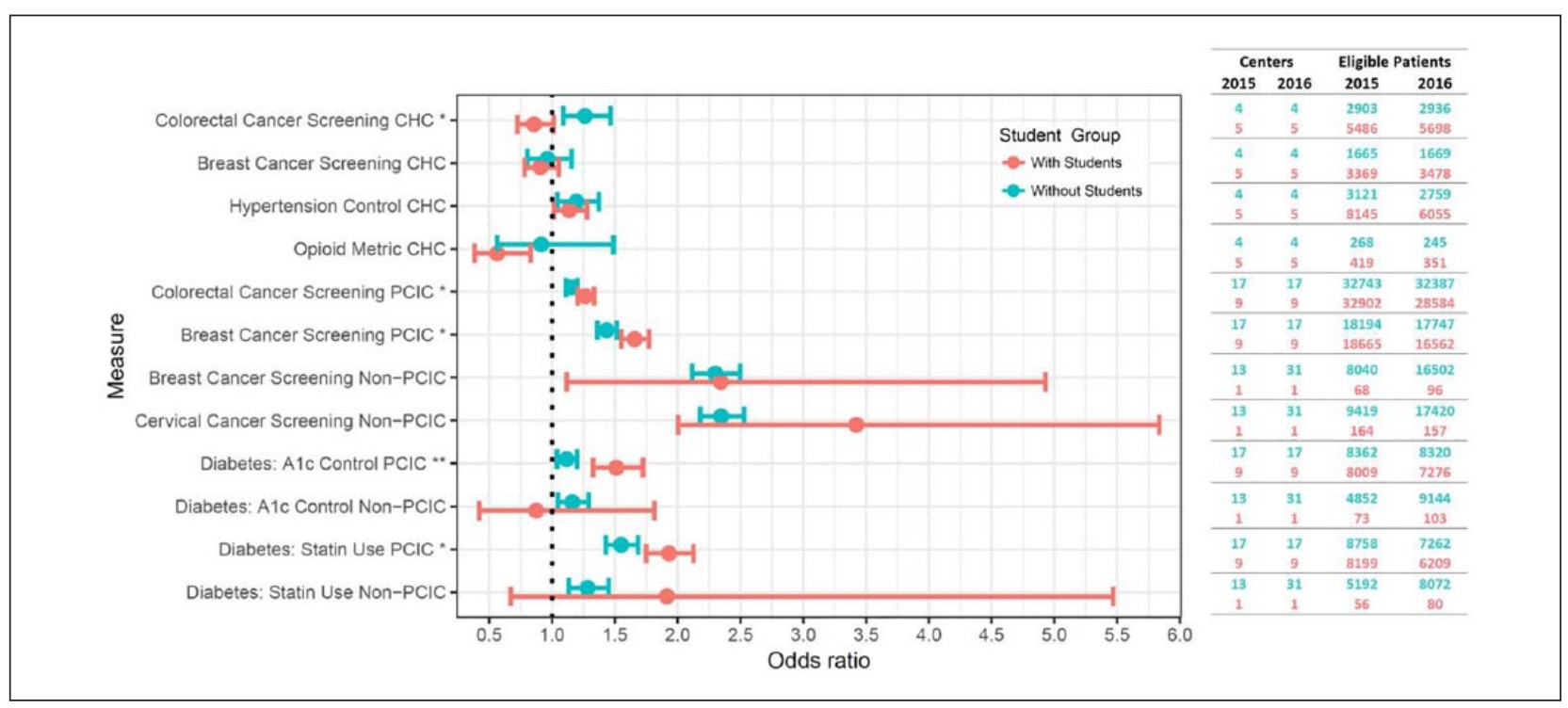

Figure 2. Model estimated odds ratios illustrating the association between change in quality measures and indirect student involvement.

The odds ratios represent the change in odds of a patient achieving appropriate screening or control goals from March 2017 to March 2016. Odds ratios $<$ I indicate improvement in quality metrics, whereas odds ratios $<I$ indicate a decrease in quality metrics between the years. $\mathrm{PCIC}$, all university academic practices (ACA) and practices owned by the university health system (AP) in the primary care improvement collaborative; non-PCIC, all AP not in the primary care improvement collaborative; $\mathrm{CHC}$, Community Health Centers. Odds ratio estimates and $95 \%$ confidence intervals are presented. $P$ values have not been adjusted for multiple comparisons.

$* \mathrm{P}<.0 \mathrm{I}, * * \mathrm{P}<.00 \mathrm{I}, * * * \mathrm{P}<.000 \mathrm{I}$ 
Table 3. Projects Not Included on the Dashboards.

\begin{tabular}{|c|c|}
\hline Improve the Number of Well-Child Checks & Improve HPV Vaccination Rates \\
\hline $\begin{array}{l}\text { mprove patient satisfaction and involvement in treatment } \\
\text { decision making (through patient survey) }\end{array}$ & Increase handwashing rate of physicians and nurses \\
\hline Improve the rate of return for patient satisfaction surveys & $\begin{array}{l}\text { Increase meningococcal vaccination rates among eligible } \\
\text { teenagers }\end{array}$ \\
\hline $\begin{array}{l}\text { Improve the numbers of patient satisfaction surveys returned } \\
\text { to the practice by handing the survey out at the end of the } \\
\text { visit }\end{array}$ & $\begin{array}{l}\text { Improve percentage of adolescents who receive age- } \\
\text { appropriate questionnaire (ie, well-child, sport participation, } \\
\text { chronic disease management) by improving workflow }\end{array}$ \\
\hline Increase number of referrals to adult day facilities & $\begin{array}{l}\text { Increase attendance of patients with congestive heart failure } \\
\text { who agree to see a nutritionist }\end{array}$ \\
\hline $\begin{array}{l}\text { Improve rates of self-management goals in patients with } \\
\text { diabetes or depression }\end{array}$ & $\begin{array}{l}\text { Increase number of eligible patients without contraindications } \\
\text { who receive influenza vaccine }\end{array}$ \\
\hline $\begin{array}{l}\text { Improve rate of dental fluoride varnish application for all } \\
\text { children at } 12,15,18,24 \text {, and } 30 \text { month well-child checks }\end{array}$ & $\begin{array}{l}\text { Reduce number of patients on high-risk medications (Beer's } \\
\text { list) }\end{array}$ \\
\hline Increase percentage of patients signed up for MyChart & Improve hepatitis B vaccination rates in diabetics \\
\hline $\begin{array}{l}\text { Improve percentage of referral notes received from outside } \\
\text { providers and entered into EMR }\end{array}$ & $\begin{array}{l}\text { Improve staff satisfaction with clinic workflow using a flagging } \\
\text { system }\end{array}$ \\
\hline $\begin{array}{l}\text { Improve system of tracking completed referrals to } \\
\text { subspecialty clinics }\end{array}$ & $\begin{array}{l}\text { Improve the number of falls evaluations and the numbers of } \\
\text { appropriate referrals for PT }\end{array}$ \\
\hline $\begin{array}{l}\text { Increase number of patients who complete labs on same day } \\
\text { as office visit }\end{array}$ & Increase hepatitis $C$ screening \\
\hline
\end{tabular}

Abbreviations: EMR, electronic medical record; HPV, human papillomavirus; PT, physical therapy.

for cervical cancer screening in practices with student involvement was $25.6 \%$ greater than the odds ratio for practices without direct student involvement $(95 \% \mathrm{CI}=$ $18.4 \%$ to $33.2 \%$ greater).

Hypertension control, a practice priority at $\mathrm{CHC}$, also showed substantial improvements in practices with student involvement. Specifically, the odds ratio comparing hypertension control in 2017 to 2016 for practices with students was $28.8 \%$ higher $(95 \% \mathrm{CI}=9.5 \%$ to $51.5 \%)$ than the odds ratio for practices without students. No change in improvement was seen for A1c control or statin usage for patients with diabetes in practices with direct student involvement (Figure 1 and online Supplementary Table 1). For the one non-collaborative practice, colorectal cancer screening improved from 2016 to 2017, but in general this improvement was not as great as compared to other non-collaborative practices.

The change in health metrics at practices that had students present, but had no students directly involved in the specific metric, also was examined (Figure 2 and online Supplementary Table 2). This analysis provides an indication of the indirect influence of students, both positive and negative, on other aspects of the practice. Substantial differences in trends were found between practice types. CHC practices with students showed a decrease in patient screening and control over all health measures, although all but colorectal cancer screening were nonsignificant. AP and ACA practices showed increases in all health metrics with the largest improvements being in cervical cancer screening (43.3\% greater odds ratio, $95 \% \mathrm{CI}=29.1 \%$ to $59.1 \%$ greater) and diabetes A1c control (35.5\% greater odds ratio, $95 \% \mathrm{CI}=16.8 \%$ to $57.1 \%$ greater). Interestingly, both A1c control and statin use in eligible patients with diabetes showed significant increases in practices with indirect student involvement, whereas no change was detected for practices with direct student involvement.

\section{Private Practices}

Although there were no dashboards from the private practices in which 52 students were placed (Table 3), student summaries and preceptor evaluations highlighted their contributions to practice improvement.

\section{Discussion}

This study demonstrates that medical students are a largely untapped resource for primary care practices that has the potential to create long-lasting positive changes for students, providers, practices, and patients alike. Practices hosting students saw greater improvements in practice quality metrics because student learning and assignments were aligned with the clinical needs. ${ }^{14}$ In Kirkpatrick's model, ${ }^{7}$ the highest level of impact attainable is clinical outcomes. Although it may seem obvious that bright and energetic students on QI teams can make a difference in clinical outcomes, it is rare to demonstrate these outcomes. Students in practices were able to 
translate classroom and online learning into practical projects that translated to improved clinical outcomes.

The implications of these results are significant. When a SOM curriculum aligns with health system needs and those needs are met by learners, measures of quality care may be affected. Additionally, medical students applying knowledge gained through the curriculum reflect Miller's assessment of the ability to do this work. ${ }^{18}$ The longer course structure improved student continuity with the practice, provider, community, and curriculum.

Present study data show significant variation in project choice from private practices to university affiliated, academic, and $\mathrm{CHC}$ practices (Table 2). Although institutional goals dictated student projects for ACA, AP, and $\mathrm{CHC}$ practices, the reasons for project choice in private practices were less clear, but student comments gave some insight into those choices. For example, one student worked in an office with 4 employees. The week prior to her rotation, the office was closed because all employees had influenza. As a result, the student was asked to improve mask wearing by patients ill with respiratory infections. This choice of project is indicative of significant practice support.

Besides QI measures, students' insights into the practice cultures not recognized by the practice leadership should be noted. For example, university dashboards were Excel files distributed monthly to all university practices. One student recognized that the providers in an AP practice did not understand how to use the macros in the Excel spreadsheets that contained the quality data. Even when the student was able to teach providers how to access their data, the percentages shown were meaningless to the providers. The student, trying to improve pneumococcal vaccine rates, calculated the number of patients needed to be immunized to get to the clinic goal, or number needed to goal (NNG). Reluctance toward improvement strategies disappeared after the calculation and the practice easily reached the clinic goal for pneumococcal vaccine rates by the end of the trimester (data not shown). The strategy was so successful that a NNG for each measure is now fed back to all university practices monthly. Anecdotal evidence suggests that NNG is a main motivator for improvement at multiple affiliated practices.

In end of course student evaluations, private practitioners frequently noted the students' abilities to navigate electronic health records to produce reports, document properly, and teach team members new processes. Notable contributions included developing a teaching tool for medical assistants on how to perform fecal immunohistochemical testing using chocolate pudding, education on 3-step documentation of foot exams in the electronic health record, and improved documentation, processes, and billing for diabetes eye exams. Students also worked on clinic efficiency with time studies, changing when and how pediatric vaccines were ordered and given, addressing patient notification of wait times to improve patient satisfaction, and developing a flagging system within a new clinic to help staff know where other staff were located. And in the era of the opioid crisis, multiple practices had students review charts for high-risk patients and develop processes consistent with the new Centers for Disease Control and Prevention opioid guidelines. ${ }^{19}$ These processes included identifying patients eligible for naltrexone, developing standard processes for educating family members on how to use naltrexone, identifying patients with multiple prescribers or on other risky medications like benzodiazepines, and identifying patients in need of urine toxicology screening or updated pain agreements.

\section{Limitations}

The research team acknowledges that the methods used to measure impact may overstate or understate student impact. Practices may have had other ongoing efforts and students may not have been the sole factor in improvement. Practices that were able to accommodate students may be inherently different than practices that were not. The team can only assess the association between student involvement and improvement in quality metrics and cannot directly attribute student involvement as the sole cause for changes. However, control practices were chosen that had similar improvement goals. All practices included in the analyses had pay for performance provider incentives, and similar levels of practice staffing, reporting, and leadership.

Understating the impact of these QI projects is also possible, especially in private practices for which there were little to no system data. For example, one student at a private practice taught nurses how to perform diabetes foot exams and realized that documentation was a key component to measurement of her outcome. She communicated with the electronic health record company to learn how to document the exam and then taught staff members how to document. Once that occurred, staff began to ask her how to document other metrics, such as depression screening and outside mammograms. She began to note that her intervention led to improvements in multiple metrics because of improved documentation. This demonstration of the adaptability and flexibility of students to changing practice needs is a valuable asset for practices and creates important learning opportunities for students.

Certain practices may have planned for students to a greater extent than others and this planning could have ramifications for overall improvement. For example, one $\mathrm{CHC}$ practice had many students work on colon cancer screening. The practices in which students continually 
worked on colon cancer screening saw dramatic improvements in screening rates. The projects and types of changes, serially and sometimes in parallel, targeted different drivers such as physician ordering, medical assistant knowledge, patient return of stool cards, and pre-visit planning. Students in all practices began to use a transitions worksheet to "pass on" advice and lessons learned to the next student. ${ }^{20}$ It is not clear what contribution planning or the transitions worksheets had on overall improvement but students frequently commented in their QIPATs on this prior knowledge when continuing the project of a previous student.

Future directions include measuring impact on faculty knowledge of QI methods, faculty recruitment and retention, and student leadership and teamwork skills.

\section{Conclusion}

In summary, the combination of an innovative, applied QI curriculum, longer rotation, faculty development, and institutional commitment can engage students in learning essential skills while practices improve quality metrics. Providers and health systems may be more likely to engage when students add value to the practice ${ }^{5}$ and positively impact patient care.

\section{Authors' Note}

Change story presentation at the American Medical Association Change Med Ed meeting; Chicago, Illinois; September 14, 2017.

\section{Acknowledgments}

The authors wish to acknowledge the physicians and leadership at Piedmont Health Services Community Health Clinic and the University of North Carolina Physicians Network who provided student learning opportunities, data for analysis, and logistical support. The authors also would like to acknowledge the UNC Practice Quality and Innovation group for their support of the students, physicians, and practices.

\section{Declaration of Conflicting Interests}

The authors declared no potential conflicts of interest with respect to the research, authorship, and/or publication of this article.

\section{Funding}

The authors disclosed receipt of the following financial support for the research, authorship, and/or publication of this article: This study was supported by a North Carolina Area Health Education Centers Campus Innovation Grant.

\section{Supplemental Material}

Supplemental material for this article is available online.

\section{ORCID iD}

Gary L. Beck Dallaghan (iD https://orcid.org/0000-0002-8539 $-6969$

\section{References}

1. Christner JG, Dallaghan GB, Briscoe G, et al. The community preceptor crisis: recruiting and retaining community-based faculty to teach medical students - a shared perspective from the Alliance for Clinical Education. Teach Learn Med. 2016;28:329-336.

2. Fazio SB, Chheda S, Hingle S, et al. The challenges of teaching ambulatory internal medicine: faculty recruitment, retention, and development: an AAIM/SGIM position paper. Am J Med. 2017;130:105-110.

3. Nutter D, Whitcomb M. The AAMC project on clinical education of medical students. https://www.aamc.org/ download/68522/data/clinicalskillsnutter.pdf. Accessed June 6, 2017.

4. Baxley EG, Dearing J, Esquivel M, et al. Joint Principles for the Medical Education of Physicians as Preparation for Practice in the Patient-Centered Medical Home. https:// www.acponline.org/system/files/documents/running_practice/delivery_and_payment_models/pcmh/understanding/educ-joint-principles.pdf. Published December 2010. Accessed May 25, 2017

5. Fazio SB, Demasi M, Farren E, et al. Blueprint for an undergraduate primary care curriculum. Acad Med. 2016;91:1628-1637.

6. Wong BM, Holmboe ES. Transforming the academic faculty perspective in graduate medical education to better align educational and clinical outcomes. Acad Med. 2016;91:473-479.

7. Kirkpatrick DL. Evaluating Training Programs: The Four Levels. San Francisco, CA: Berrett-Koehler; 1994.

8. Johl K, Grigsby RK. Engaging learners in health system quality improvement efforts. Acad Med. 2017;92 593-597.

9. Gould BE, Grey MR, Huntington CG, et al. Improving patient care outcomes by teaching quality improvement to medical students in community-based practices. Acad Med. 2002;77:1011-1018.

10. Hostetter M. In Focus: Quality improvement training for medical students and residents. http://www.commonwealthfund.org/publications/newsletters/qualitymatters/2010/october-november-2010/in-focus Accessed September 6, 2017.

11. Headrick LA, Barton AJ, Ogrinc G, et al. Results of an effort to integrate quality and safety into medical and nursing school curricula and foster joint learning. Health Aff (Millwood). 2012;31:2669-2680.

12. Dyer C, Gregory G, Aud M, et al. Using fall prevention for interprofessional patient safety training at the bedside. Presented at: 16th Annual International Scientific 
Symposium on Improving the Quality and Value of Health Care; Orlando, FL; December 6, 2010.

13. Association of American Medical Colleges. Learning from teaching. https://www.aamc.org/initiatives/cei/learning/. Accessed November 13, 2017.

14. Lin SY, Schillinger E, Irby DM. Value-added medical education: engaging future doctors to transform health care delivery today. J Gen Intern Med. 2014;30:150-151.

15. Skochelak SE, Hawkins RE, Lawson LE, Starr SR, Borkan JM, Gonzalo JD. Health Systems Science. 1st ed. New York, NY: Elsevier; 2016.

16. Institute for Healthcare Improvement. Open school. http:// www.ihi.org/education/IHIOpenSchool/Pages/default. aspx Accessed November 13, 2017.
17. Leenstra JL, Beckman TJ, Reed DA, et al. Validation of a method for assessing resident physicians' quality improvement proposals. J Gen Intern Med. 2007;22:1330-1334.

18. Miller GE. The assessment of clinical skills/competence/ performance. Acad Med. 1990;65(9 suppl):S63-S67.

19. Centers for Disease Control and Prevention. Guideline for prescribing opioids for chronic pain. https://www.cdc.gov/ drugoverdose/pdf/guidelines_factsheet-a.pdf Accessed September 6, 2017.

20. Bernstein C, Shaheen S. Development of a transitions document for medical student quality improvement projects in primary care practices. Presented at: Southern Society of General Internal Medicine Regional Meeting, New Orleans; New Orleans, LA; February 10-12, 2017. 